these particles exist, and what determines their qualities.

The author is most compelling when he tackles these broad historical trends in the scope and purpose of physical theorizing. But these large themes only occasionally come to the fore. It is also unclear what kind of reader he imagines he's writing for. Discussing the emergence of quantum mechanics, for example, he observes in passing that Dirac's formulation derived more from the poissonian than the hamiltonian version of classical mechanics, a remark that will mean something only to those who already know what it means.

Readers with some general knowledge of the development of physics will find in Roger
Newton a companionable guide who points out familiar and vaguely remembered landmarks and offers occasional illuminating commentary. If his aim was to enlighten a less wellversed audience, he could have said more by saying less.

David Lindley is a freelance writer in Alexand ria, Virginia, USA.

\section{On the right path}

The Best of All Possible Worlds:

Mathematics and Destiny

by Ivar Ekeland

Chicago University Press: 2006.191 pp. $\$ 25$

\section{Joseph Mazur}

Thomas Aquinas argued that evil helps the good in the world. St Augustine maintained that God brought evil into the Universe to bring about a greater good. And Gottfried Leibniz, after confessing in his Theodicy that God was free to create a world without evil, asserted that the best plan for a Universe is " not always that which seeks to avoid evil, since it may happen that the evil is accompanied by a greater good". He concluded that of all the worlds God could have created, the one we live in is "the best of all possible". We remember this phrase best through Candide, Voltaire's satire of Leibniz's philosophy: "If this is the best of possible worlds," asks Dr Pangloss, Candide's teacher, "what then are the others?"

How much evil is needed to maximize good? It seems that God has chosen one world from an infinite collection of possibilities by seeking to minimize evil under the constraint of maximizing good. The eighteenth-century French philosopher Pierre-Louis Moreau de Maupertuis gave us the principle of least action: in all natural phenomena, a quantitycalled 'action' - for him, the product of mass, distance travelled and velocity - tends to be minimized. In his view, God, being the supreme mathematician, had created the "best of all possible worlds" by insisting that everything in it obey the principle of least action, an economy of effort - a metaphysical rule designed to support the laws of mechanics.

In The Best of All Possible Worlds, Ivar Ekeland skilfully traces the historical developments of de Maupertuis' principle as it matured from a metaphysical directive in physical two- or threedimensional space to a mathematical principle in a conceptual space where the action is not just minimized but stopped altogether. He then tracks it further to our modern notions of randomness measured by probabilities. This complex story can be read with a minimum of effort, and we are left feeling that Maupertuis' principle works, even though we know that randomness is hardly compatible with minimizing actions. Ekeland - a distinguished mathematician and director of the Pacific Institute for Mathematical Sciences in Vancouver - goes on to say: "If there is a God, he has left no tracks in the laws of physics; or if he has, he has covered them up very well."

The real question behind Ekeland's magnificent book is this: how does nature do it? Of all the possible actions, from travelling photons to rolling billiard balls, how does nature choose what path to follow? You are reading a book review of Ivar Ekeland's The Best of All Possible Worlds, but how did you get to be reading it at this precise moment and in this place? Was it a dictate of nature that led to this action? Was

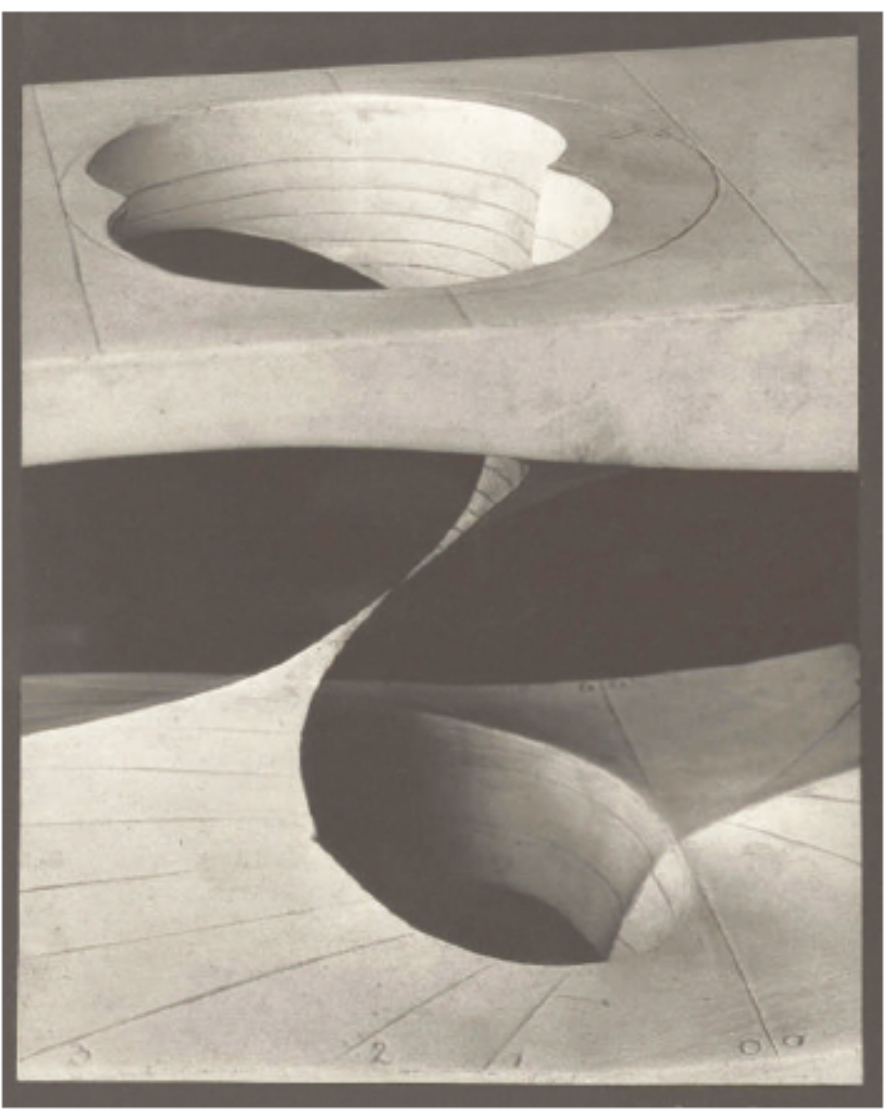

it the perturbations caused by the proverbial butterfly flapping its wings over the Pacific? Did nature have some purpose in making you read it?

Ekeland says 'no' to all three questions. Yes, some mechanical systems are modelled bycriteria of optimizing performance that could be interpreted as minimizing some kind of action or energy. But most mechanical systems of the world are unpredictable. "Since classical mechanics has dealt exclusively with integrable systems for so many years, we have been left with wrong ideas about causality, writes Ekeland; we have ignored non-integrable systems - those that do not admit exact solutions to differential equations. World events are not linear. History does not follows parallel causal chains; each event " ${ }^{\text {is like the trunk of a tree, }}$ plunging a network of roots deep into the past, and raising a crown of branches high into the future.". Ekeland refutes Blaise Pascal's remark that if Cleopatra had a shorter nose, the world would be very different.

Ekeland competently weaves the philosophical views of scientists through the warp of metaphysics dealing with nature's directives. Wehear how Ernst Mach believed that the role of science is to explain the facts as accurately and simply as possible, and how Henri Poincaré believed that science is not really about objective reality or truth, but rather the ease and expediency of human comprehension. Over the weave, Ekeland embroiders some lively anecdotes involving illustrious individuals and great historical moments, ranging from the Peloponnesian Wars and Venetian concessions to the Hapsburg emperor Maximilian to Darwin's voyage to the Galapagos. His explanations are clear and elegant, in the brilliant, effortless manner of Richard Feynman, and his prose is fluid, exhilarating and suspenseful. I tried to put this superb book down after chapter 4 but couldn't. It was as if some compelling force of nature had a purpose, an opposing directive in the best of all possible worlds.

Joseph Mazur is the author of Euclid in the Rainforest. He teaches mathematics at Marlboro College, Marlboro, Vermont 05344,USA. 